\title{
Los temas de la memoria colectiva del Golpe de Estado de 1976 en Argentina EN FUNCIÓN DE LA IDEOLOGÍA Y LAS GENERACIONES
}

\author{
Themes of the COlLective memory of the coup d'ÉtAT Of 1976 in ARgentina \\ AS A FUNCTION OF IDEOLOGY AND GENERATIONS
}

\author{
Felipe JuAn Muller* y Federico Bermejo**
}

\begin{abstract}
*PhD en Psicología. Miembro de la Carrera del Investigador Científico del Consejo Nacional de Investigaciones Científicas y Técnicas (CONICET) e Investigador y Profesor a cargo de la asignatura Producciones Culturales y Subjetividad en la Universidad de Belgrano (UB). E-Mail: felipejmuller@gmail.com

${ }^{* *}$ MA en Investigación en Psicología, Licenciado y Doctorando en Psicología. Asistente de Investigación y Coordinador Docente de la asignatura Producciones Culturales y Subjetividad en la Universidad de Belgrano (UB). Profesor Adjunto de la asignatura Psicología de la Interacción Social y de los Pequeños Grupos en la Universidad del Salvador (USAL). Universidad de Belgrano, Departamento de Investigaciones, Zabala 1837, Piso 7 Of. 14
\end{abstract}

(1426) Ciudad Autónoma de Buenos Aires, República Argentina.

\section{RESUMEN}

El recuerdo del Golpe de Estado de 1976 en Argentina ofrece una oportunidad para estudiar los procesos de formación y composición de la memoria colectiva. En el trabajo que se informa se estudió cómo los contenidos del recuerdo del golpe son afectados por dos factores: las generaciones que lo recuerdan y la ideología política de los participantes. Con este objetivo, se solicitó a 52 participantes argentinos y de ambos sexos que completaran una tarea de Recuerdo Libre en torno a los hechos del Golpe de Estado de 1976. Se dividió la muestra en dos grupos de 26 sujetos, uno estuvo compuesto por personas que vivieron durante esos años (mayores de 48 años) y el otro, por personas de una generación que no vivió aquella época (menores de 30). Se consideró también la ideología política de los participantes (Izquierda o Derecha). Se utilizó un enfoque de análisis descriptivo, centrado en analizar el contenido del recuerdo, considerando qué temas / ideas principales lo conformaban. Los resultados muestran una mayoría de temas comunes al recuerdo de los distintos grupos. Estos elementos comunes conformarían una memoria nacional del golpe. También muestran que la generación y la ideología política promueven temas / ideas principales propios de cada grupo. Aquellos de la generación mayor recordaron más temas / ideas principales de tipo contextual y emocional / afectivo. Los de la generación menor recordaron en mayor medida los hechos acontecidos durante la dictadura. Los sujetos del grupo de Izquierda recordaron temas / ideas principales vinculados a la violencia de Derecha y más aspectos contextuales que los del grupo de Derecha. Se propone que hay un sistema de memoria nacional que operaría en los sujetos y que es afectado por las metas y objetivos de cada grupo.

Palabras clave: Memoria colectiva; Generaciones; Ideología; Temas; Golpe de Estado; Argentina.

\section{ABSTRACT}

Argentina, as well as others Latin American countries, lived through a military dictatorship 
from 1976 to 1983 . Because of the magnitude of its consequences, it is a period of the Argentinean history that is still discussed by its citizens and that has a place in the educational curricula of the country now. Moreover, its current importance is evident, for example, as shown in the ongoing trials for the responsibilities of the crimes committed by the militaries so many years ago, and the frequent news of people recovering their stolen identity after being born in captivity during those years and being raised by families that appropriated them. A collective memory of the events taking place over those years is in the process of constitution and development. As people talk about it, as new information is spread on the news, as justice works over those committing the terrible crimes during that period in Argentina, a collective memory of the 1976 coup d'état takes shape. One aim of the present work was to contribute to the study of the collective memory of the coup d'état of 1976 in Argentina. Even though this issue has received attention in previous studies, an empirical approach towards it that focuses on the discourse of the memories of the participants, conforms a new contribution. Another aim of this study was to contribute to the study of collective memory from a psychological perspective. Recalls of the coup d'état of 1976 in Argentina offer one of those opportunities to study the processes of formation and constitution of collective memory. In the present study, we are interested in studying how the contents of the recall of the coup d'état are affected by two specific factors: generations and ideology. Our interest is to study how similar and different are the memories for those events for different generations of citizens. We are basically considering those who lived through those years and those who learned about those same events indirectly, through books, documentary, news, etc. We are also interested in studying how much political ideology can affect the recall of those events. In that, we considered the basic ideological distinction between left and right. The dependent variable was a concrete aspect of the content of the recall: themes / main ideas. A total of 52 subjects participated in the study. The sample was divided in two groups, one of which was constituted by subjects who lived-through those years. This was the older generation group. The other group conformed the younger generation and was integrated by subjects that didn't live through those years because they were not yet born. At the same time, people from the left and right ideologies composed each of these two groups. Participants completed a Free Recall Test, where we asked them to recall all of what they could remember about the events around March 24, 1976. We focused on analyzing the content of the recall, considering the themes / main ideas that configured it. There are common elements of the recall that seem to configure a national memory of the coup d'état. However, generations and political ideology promoted themes / main ideas typical of each group. Those of the older generation remembered more contextual and emotional / affective themes / main ideas. Those of the younger generation remembered more facts that took place during the military dictatorship. People with a left wing ideology remembered more themes / main ideas related to the 'Right wing violence' and more contextual aspects than those with a right wing ideology. A national memory system that would operate in the citizens and that is affected by the goals of each group is proposed.

Key words: Collective memory; Generations; Ideology; Themes; Coup d'état; Argentina.

El marco general del estudio de la memoria colectiva está dado por lo que algunos historiadores han denominado el boom de la memoria (memory boom). Así se define al movimiento que comienza a fines de la década de 1970, que toma como objeto de estudio tanto a la memoria individual como a la social y lo hace desde una multiplicidad de disciplinas. La versión más establecida de este giro sobre la memoria sostiene una declinación, en tiempos de posguerra, de narrativas de progreso y bienestar por medio de un Estado cada vez más abarcador y una vuelta al pasado para buscar fortalecer la propia legitimidad (Olick, Vinitzky-Seroussi \& Levy, 2011). Esa mirada al pasado colectivo se orienta a una búsqueda de identidades reprimidas, demandas postergadas, heridas abiertas y procesos judiciales pendientes. 
En distintos países se encuentran estudios que abordan problemáticas que tienen que ver con cómo se recuerda el pasado y cómo se opera frente a él (Hirst \& Manier, 2008). En Alemania se sigue lidiando con las atrocidades del Holocausto; en Sudáfrica, con la confrontación del Apartheid; en España, con la Guerra Civil; en los países de Europa del Este, con los colaboracionistas de los regímenes comunistas (Rosenberg, 1995). En todos estos casos, lo que es problemático es la forma que toma la memoria colectiva de un pasado conflictivo en algunos casos, siniestro en otros, y la incidencia que tiene el conjunto de recuerdos que la conforman sobre la identidad colectiva de cada uno de estos países y sus comunidades (Hirst \& Manier, 2008).

De la misma manera, Argentina y los demás países latinoamericanos que han atravesado sangrientas dictaduras se encuentran, con distintos procedimientos y con mayor o menor ahínco, lidiando con su pasado (es el caso de los juicios en Argentina, la recuperación de hijos de desaparecidos, la reconstrucción de los hechos, etc.) y, al tiempo, van conformando una memoria nacional del mismo. Siendo la memoria nacional una forma de memoria colectiva, el estudio que se informa se orienta a hacer una contribución a este campo en desarrollo, investigando en la memoria colectiva del Golpe de Estado del 24 de marzo de 1976, llevado a cabo por los militares contra el gobierno democrático de Isabel Perón.

En este sentido, el objetivo del trabajo realizado fue doble. Con respecto al primer objetivo, es contribuir al campo emergente de la memoria colectiva desde una perspectiva psicológica (ver Hirst \& Manier, 2008). La memoria colectiva ha sido estudiada desde distintas disciplinas, pero recientemente la Psicología comienza a hacer su contribución, partiendo de considerar que si bien la memoria colectiva se refiere a un conjunto de recuerdos compartidos, son en última instancia los individuos quienes recuerdan. Allí la Psicología encuentra el lugar desde donde hacer su aporte.

En estudios previos se abordó el impacto que tienen las conversaciones entre los miem- bros de un grupo en el desarrollo de la memoria colectiva y también la incidencia de los roles conversacionales, las discusiones durante el recuerdo, la calidad de los recuerdos y la provisión de información complementaria a los participantes (Muller \& Bermejo, 2012; Muller \& Camarada, 2011; Muller \& Hirst, $2010,2014)$. En la investigación que se informa interesó estudiar la contribución que hacen a la memoria colectiva las distintas generaciones, como así también saber cómo la ideología de los grupos incide en su conformación.

Y el segundo objetivo fue estudiar el recuerdo concreto que los argentinos tienen de los hechos del golpe de 1976, haciendo así también una contribución específica al estudio de la memoria colectiva del golpe.

Un problema inicial que el investigador confronta cuando se orienta al estudio de la memoria colectiva, está dado por su definición, por la proliferación de usos del término a partir de que Halbwachs (1950 / 1980), desde la Sociología, inicia el estudio de la misma (Berliner, 2005).

El trabajo que se presenta está centrado en la definición de Hirst y Manier (2008), para quienes la memoria colectiva se refiere a las memorias compartidas por una comunidad y que tienen incidencia en la identidad de esa comunidad (ver también, Herranz \& Basabe, 1999; Monsegur, Espinosa \& Beramendi, 2014). Hirst y Manier (2002) han propuesto una serie de distinciones a la hora de abordar el estudio de la memoria colectiva desde una perspectiva psicológica. Elaborando en los sistemas de memoria individual, establecieron una distinción entre memoria colectiva episódica, memoria colectiva semántica vivida (MCSV) y memoria colectiva semántica distante (MCSD). La memoria colectiva episódica hace referencia a los eventos experimentados directamente por un grupo. Este es el caso por ejemplo de un grupo de amigos que comparte el recuerdo de un viaje que hicieron juntos $y$, en tanto recuerdos compartidos, contribuyen a conformar la red de amigos que conforma al grupo y a la identidad grupal. El problema con este tipo de memoria colectiva es que una comunidad en la que 
todos sus miembros posean recuerdos colectivos episódicos sería una comunidad pequeña, ya que no siempre en los grupos grandes todos los miembros tienen la misma experiencia. Por eso, las memorias colectivas episódicas rara vez son parte de una memoria nacional.

La memoria nacional está conformada básicamente por la memoria colectiva de tipo semántico, ya sea de tipo vivido o de tipo distante. Según Hirst y Manier (2002), la primera se refiere a eventos que ocurren durante la vida de un individuo y en un tiempo en el cual ese individuo es capaz de entender al mundo en un sentido amplio. Estos recuerdos no se experimentan directamente ( si así fuera, cumplirían los criterios para ser recuerdos colectivos episódicos). Por ejemplo, la imagen del ex presidente argentino Fernando De la Rúa dejando la Casa Rosada en helicóptero fue vista por la gran mayoría de los argentinos, pero solo una minoría estuvo en la Plaza de Mayo esa noche. Si la partida del helicóptero hubiera sido presenciada por todos los argentinos, la memoria nacional alrededor de los hechos de diciembre de 2001 estaría conformada por la memoria colectiva episódica. Pero en realidad, muchos vieron la partida del helicóptero en la televisión, en la foto de los diarios del día siguiente y volvieron a verla en documentales o al leer notas que recuerdan los episodios de diciembre de 2001 en Argentina. De allí que la memoria nacional de aquellos hechos esté conformada mayormente por una memoria colectiva semántica vivida.

La memoria colectiva semántica de tipo distante se refiere a recuerdos de eventos del pasado que no fueron directa o indirectamente experimentados durante la vida de una persona. Por ejemplo, para los argentinos menores de 40 años, los recuerdos de la muerte de Juan Domingo Perón en 1974 constituyen una memoria colectiva semántica distante, ya que sucedió antes de su nacimiento y conforma un evento que ha marcado el destino de los argentinos, cuando uno considera los eventos que se sucedieron tras su muerte.

Como en otro trabajo (Muller, Bermejo \& Hirst, 2015), interesa aquí continuar el estudio de las características de la memoria colectiva semántica de tipo vivida y de tipo distante. El Golpe de Estado de 1976 permite una gran oportunidad para su estudio, ya que existe una parte de la población que ha vivido a través de los acontecimientos (lived-throughness) de aquellos años (portadores de memoria colectiva episódica y memoria colectiva semántica vivida) y hay otra parte que no lo ha hecho y recuerda el golpe a través de fuentes indirectas de las que se ha nutrido (portadores de memorias colectivas semánticas distantes). Para los argentinos mayores de 48 años (la generación mayor en el estudio realizado), los recuerdos del golpe conforman la memoria colectiva semántica de tipo vivido (para algunos, esta memoria puede ser de tipo episódico, como es el caso de aquellos que han sido víctimas directas de la violencia de aquellos años). Para los que tienen menos de 30 años (la generación menor), los recuerdos colectivos son también semánticos pero de tipo distante, ya que estas personas nacieron luego del restablecimiento del orden democrático. Resulta de interés estudiar cómo los recuerdos de las distintas generaciones contribuyen a la memoria colectiva. El estudio que aquí se informa se centró en los temas / ideas principales que hacen al recuerdo colectivo del golpe.

\section{DEL TIPO DE RECUERDO Y LAS GENERACIONES Y SU CONTRIBUCIÓN A LA MEMORIA COLECTIVA}

Tal como ya se señalara, un punto de partida indispensable para el estudio de la contribución al recuerdo colectivo por las distintas generaciones es la fuente del mismo. La distinción entre memoria colectiva de tipo semántico vivido y de tipo semántico distante. Halbwachs (1925 / 1992, 1950 / 1980) distingue entre el recuerdo autobiográfico (vivido) y el recuerdo histórico (distante) en sus trabajos sobre memoria colectiva. Estos serían justamente dos fuentes de la misma. En cuanto a sus características principales, el recuerdo autobiográfico es aquel que se basa en la experiencia directa, o que está relacionado directamente con aquello que se quiere recordar. Por otro lado, el recuerdo histórico es aquel 
cuya fuente es indirecta, como pueden ser los registros escritos (manuales de historia, por ejemplo) u otras fuentes, y que se mantiene vivo en la memoria por medio de conmemoraciones y distintos tipos de celebraciones grupales.

Las distintas investigaciones en torno al tipo de recuerdo que conforma la memoria colectiva se ocupan de mostrar como un tipo de recuerdo u otro afecta a la memoria colectiva. Son escasos los estudios que desde la Psicología estudian esta distinción, siendo más frecuentes en disciplinas vecinas. Schuman y Scott (1989) hicieron una encuesta preguntando sobre los eventos más significativos e importantes de los últimos 50 años. Encontraron un efecto generacional en el análisis de sus datos. Los eventos más significativos para los participantes fueron aquellos que ocurrieron durante la adolescencia tardía y la adultez temprana. Los resultados indican que a los hechos recordados a través de memorias semánticas de tipo vivido se les atribuye una mayor importancia histórica. En un estudio reciente, Zaromb, Butler, Agarwal y Roediger III (2014) investigaron en Estados Unidos los recuerdos en jóvenes (media de edad: 20.3 años) y adultos mayores (media de edad: 76.3 años) sobre tres hechos históricos, como lo son la Guerra Civil estadounidense, la Segunda Guerra Mundial y la Guerra de Irak. De los tres hechos, la Segunda Guerra Mundial (1939-1945) es el único para el cual los jóvenes disponían de memorias colectivas semánticas distantes, mientras que los adultos mayores disponían de memorias colectivas semánticas vividas. Centrarse en los recuerdos de ambos grupos sobre dicho evento permitió a los autores comparar ambos tipos de memoria colectiva. Los participantes respondieron por los diez eventos más salientes para cada período, así como por su valoración. Con respecto a la valoración, hubo diferencias significativas entre ambos grupos con respecto a la Segunda Guerra Mundial. La generación mayor brindó valoraciones más positivas que la generación menor para los eventos de este mismo hecho histórico. Por ejemplo, el que evidenció mayor diferencia fue la bomba de Hiroshima. Zaromb y colaborado- res (2014) intentan explicarlo en términos de la narrativa que tienen de la guerra los sujetos. Los mayores, para quienes Hiroshima es una memoria colectiva de tipo semántica vivida, habrían organizado este evento centrándose en el final de la guerra para los Estados Unidos, mientras que la generación joven lo habría hecho centrándose en ese hecho como símbolo de la destrucción.

Stone, van der Haegen, Luminet y Hirst (2014) y Schuman y Scott (1989) han examinado el contenido de los recuerdos colectivos y observaron que aquellos que viven o atraviesan los eventos de un episódico histórico tienden, por sobre aquellos que no lo hicieron, a incluir en sus recuerdos información personal y autobiográfica. Por otro lado, $\mathrm{Mu}-$ ller y colaboradores (2015) encontraron que los recuerdos de aquellos que han vivido los eventos contenían más enunciados que contextualizan a los mismos.

Teniendo en cuenta también las valoraciones que hacen los participantes sobre cierto período histórico, se investigó la distinción entre tipos de recuerdos en base a las valoraciones que hicieron distintas generaciones sobre la situación de Argentina en 1976. En la misma línea que Zaromb y colaboradores (2014) se encontró que la memoria colectiva semántica vivida y la memoria colectiva semántica distante contribuyen de manera distinta a la memoria colectiva. Los recuerdos basados en la experiencia vivida tendrían la capacidad de matizar las valoraciones específicas que hicieron los participantes sobre las dimensiones que fueron elegidas por ellos mismos para evaluar aquella época o sobre dimensiones propuestas por los investigadores, como por ejemplo Bienestar Económico. En cambio, en las valoraciones generales, tanto los sujetos con memorias colectivas semánticas vividas como aquellos con memorias colectivas semánticas distantes se pronunciaron de forma igualmente negativa sobre la Argentina de 1976 en comparación con otros períodos del país (Muller \& Bermejo, 2013; Muller, Bermejo \& Addai, 2012).

Wertsch $(1998,2002)$ también distingue entre memoria colectiva de los eventos vividos y memoria histórica de hechos de tiempos 
previos. Sostiene que los eventos ocurridos durante la vida de un individuo parecen tener un impacto único en la memoria individual y en la memoria colectiva de una generación. En este sentido, la memoria vivida tiene siempre una posición privilegiada. Wertsch estudia un debate en los años 90 en torno a una muestra en el National Air and Space Museum en Washington. La muestra tenía como tema de organización la decisión de lanzar la bomba atómica sobre Hiroshima y Nagasaki en 1945. Para ello, los organizadores de la muestra consultaron a historiadores en la recolección de material para la misma. La tensión y el debate comenzaron cuando los veteranos de la Segunda Guerra Mundial se enteraron de que parte de la muestra se orientaba a mostrar que Estados Unidos había promovido el ataque a Pearl Harbor, y por lo tanto tenía responsabilidad en el comienzo de las hostilidades. Finalmente, se realizó una muestra mucho más medida y atemperada que la originalmente planeada. Más allá de las cuestiones políticas, desde el punto de vista de la distinción que interesa, según Wertsch, los veteranos se apoyaron en la memoria autobiográfica o vivida, y es entonces que su voz reverberó en el público de una manera distinta a la voz de los historiadores profesionales. Aquellos que viven los eventos parecen obtener un estatus particular en los debates culturales y políticos.

\section{IDEOLOGÍA Y MEMORIA COLECTIVA}

Si las generaciones son un factor insoslayable en el estudio de la memoria colectiva, la ideología también lo es. Fue Halbwachs (1925 / 1992, 1950 / 1980) quien se encargó de establecer que el recuerdo es inevitablemente ideológico. Ya dentro del campo de la Psicología Social, Billig (1990) entiende que la ideología misma es una forma de memoria social, ya que constituye lo que es colectivamente recordado y olvidado.

Los trabajos que relacionan esquema y memoria nos permiten anticipar que la ideología política de una persona afectará el recuerdo de cualquier evento cargado políticamente (Jost, Federico \& Napier, 2009; van Dijk, 1998).
Jost y colaboradores (2009) plantean que en la literatura científica se ha considerado que la ideología política se representa en la memoria como un tipo de esquema cognitivo. Consideran que se trata de una estructura de conocimiento aprendido que consiste en una red interrelacionada de creencias, opiniones y valores. Ferguson, Carter y Hassin (2009) a su vez, sostienen que el conocimiento ideológico podría activarse en la memoria de forma implícita, como un esquema, y por lo tanto influir en las actitudes, juicio y comportamiento sin conocimiento, intención o conciencia por parte del individuo. Un trabajo relevante es el de van Dijk (2003, 2005, 2008), que ofrece una herramienta de análisis del discurso en la cual memoria social, ideología y discurso quedan relacionados. Para él, la ideología son creencias sociales compartidas e implícitas. Se refieren a aspectos políticos y sociales que son relevantes para un grupo y su existencia. Al mismo tiempo, mientras que la ideología promueve un énfasis en los aspectos positivos del propio grupo, resalta los aspectos negativos de los otros grupos. Otra característica de la ideología es que puede ser política, religiosa, económica, etc. La ideología política es relevante para los intereses de la investigación realizada.

Al respecto, Bobbio (1996) entiende que el campo ideológico / político se divide en derecha e izquierda. Estos son términos antitéticos, excluyentes y exhaustivos del universo ideológico (Bobbio aclara que la noción de Centro no invalida esta antítesis). Ambas, derecha e izquierda, plantean programas opuestos en relación con los distintos problemas, cuya solución es parte de la vida cotidiana. La izquierda es identificada como compuesta por una creencia general acerca de la posibilidad de alcanzar una igualdad universal entre las personas. La derecha se sustenta en la defensa sostenida de las costumbres y la tradición. Esta distinción resulta relevante al momento de incluir la ideología como un factor que afecta a la memoria colectiva.

Manzi y colaboradores (2004) estudiaron la ideología política y su relación con la memoria colectiva del golpe de Estado de 1973 en Chile. Dividieron la muestra en dos grupos 
(Centro-izquierda y Derecha) y consideraron el nivel de involucramiento político de los participantes durante esos años (mayor o menor nivel) e indagaron en los recuerdos que giraban en torno al golpe de Estado de Pinochet. Haciendo un análisis cualitativo del recuerdo de los hechos alrededor del golpe, sus causas y sus consecuencias, sus resultados muestran que hay un elevado nivel de coincidencia entre ambos grupos sobre los hechos (aquellos eventos que los entrevistados mencionan que ocurrieron el 11 de septiembre de 1973), como por ejemplo, el bombardeo al Palacio de la Moneda, pero que ambos grupos difieren en las causas y las consecuencias del golpe. Así resultan dos versiones de la memoria colectiva, en función de la ideología reportada por los participantes.

\section{LOS TEMAS DE LA MEMORIA COLECTIVA}

Al igual que en un trabajo reciente (Muller et al., 2015), en este estudio el objetivo fue analizar el contenido de la memoria colectiva de distintas generaciones y de participantes con distintas ideologías. Según Wertsch (2002), las personas que recuerdan un evento pasado nacional cuentan una historia, de la misma manera en que lo hacen cuando recuerdan el pasado personal. Es así que desarrollan una narrativa o discurso. En este estudio se realizó un análisis del discurso de estos recuerdos.

Para ello se utilizó un esquema de análisis del discurso basado en van Dijk (2003), y al cual se le incorporaron criterios propios. Para van Dijk, el discurso o relato producido sobre un hecho posee diversos niveles, y es por ello que las personas disponen de múltiples procedimientos para agregar o quitar énfasis a los significados de estos discursos. Hay distintos elementos de análisis en un discurso: actores, temas, sinonimia, evidencia, negaciones, nivel de descripción y detalle y ejemplos, entre otros. En este caso, se tomó como unidad de análisis (variable dependiente) a los temas / ideas principales presentes en los recuerdos en torno al golpe de Estado de 1976 producidos por los participantes y se es- tudió si variaban o no en función de dos factores: las generaciones y la ideología.

La relevancia del estudio está dada, en un sentido amplio, por su contribución al campo emergente del estudio de la memoria colectiva desde una perspectiva psicológica. Es notorio que los psicólogos cognitivos han estudiado la memoria autobiográfica, reconociendo su importancia para la identidad individual, pero llamativamente ha quedado postergado el estudio de la memoria colectiva del pasado nacional, de importancia crucial para la identidad nacional (Hirst \& Manier, 2008; Olick et al., 2011), a pesar de contar con algunos estudios relevantes además de los ya citados (cf., Páez, Valencia, Pennebaker, Rimé \& Jodelet, 1998).

Para fundamentar su relevancia en un sentido más específico, habría que mencionar justamente la falta de estudios empíricos desde la Psicología de la memoria colectiva del Golpe de Estado de 1976 en Argentina. Esta falta podría deberse a que se trata de un campo de constitución reciente. Si bien el campo de la memoria con relación a este período histórico del país ha sido objeto de estudio (por ejemplo, cf., Vezzetti, 2009), no lo fue desde un análisis de la narrativa o del discurso de estos recuerdos. Esta escasez de investigaciones también se evidencia en otros países latinoamericanos que han sufrido dictaduras militares. Una cercana y notable excepción es el estudio de Manzi y colaboradores (2004) en Chile, reportado previamente. En suma, si bien existen estudios sobre la memoria colectiva que han analizado la incidencia en el recuerdo de las generaciones (Schuman, Be1 li \& Bischoping, 1998; Schuman \& Scott, 1989), de la ideología política (Manzi et al., 2004), que se han centrado en el recuerdo del pasado de una nación (ver Páez et al., 1998) o bien que han utilizado como herramienta el análisis del discurso (Iñiguez, Valencia \& Vázquez, 1998), la consideración de todos estos aspectos y su aplicación al estudio de los temas / ideas principales que emergen del recuerdo del último golpe de Estado en la Argentina resulta novedoso. Se realizó entonces, un análisis del contenido de los recuerdos del golpe, considerando los temas e ideas 
principales. El discurso cuenta con significados más globales que aquellos de las palabras y frases. Los temas representan la información más importante del discurso. Se diferencian de las ideas más abstractas en que los temas se representan en proposiciones y las ideas abstractas en una palabra (por ejemplo, Inmigración, Discriminación, etc.). Si bien van Dijk diferencia temas de ideas abstractas (o ideas principales), en el trabajo que se informa se consideró a ambos como unidad de análisis. Por ejemplo, una frase como la siguiente representaría un tema tal como Violencia en el fútbol: 'Desde hace años, se han producido numerosos hechos de violencia en los estadios de fútbol, que han dejado como saldo numerosas víctimas y pérdidas económicas'. Otro ejemplo sería la categorización de la siguiente afirmación como el tema $D e-$ serción escolar: 'Muchos adolescentes abandonan la escuela, por diversas razones, antes de finalizar sus estudios secundarios'. Más simplemente, el término racismo es una idea abstracta. Cuando una idea de esta índole aparece en el discurso, constituye una categoría separada con el mismo nombre (en este caso, racismo), según el enfoque seguido en la presente investigación.

Considerando los resultados que resaltan la homogeneidad de la memoria colectiva (Manzi et al., 2004; Muller et al., 2015) resultó de interés estudiar cuáles eran los temas / ideas principales proporcionalmente más recordados según las generaciones (considerando los recuerdos colectivos semánticos de tipo vivido o de tipo distante) y según la ideología (grupos ideológicos de Derecha y de Izquierda) de los participantes. Es decir, dado que era posible que todos los grupos que componen la muestra recordaran la desaparición de personas, resultó de interés estudiar si este tema ocupaba una mayor proporción que otros temas / ideas principales en el recuerdo de cada grupo. Estudiar la proporción que ocupaba un tema / idea principal en el recuerdo de cada grupo permitió identificar aquellos temas / ideas principales comunes al recuerdo colectivo, y a la vez aquellos temas / ideas principales que son propios a un grupo generacional o ideológico.
En principio, al pensar en las diferencias en el recuerdo según las generaciones, se puede conjeturar que aquellos que han vivido durante la última dictadura militar en Argentina, tendrían recuerdos más elaborados que se reflejarían, por ejemplo, en una mayor proporción de temas / ideas principales que permitan una contextualización del golpe. Estos serían los contenidos del lived-through-ness (Muller et al., 2015). Por otro lado, aquellos que han aprendido de los acontecimientos del golpe por medio de las fuentes indirectas, tenderían a recordar una serie de hechos destacados por esas mismas fuentes. Estos participantes han aprendido acerca del golpe por medio de textos en la escuela secundaria (González, 2012) y por lo tanto, tienen la ventaja que provee la educación formal, en donde los manuales y libros de texto ofrecen estructura y organización a los eventos en cuestión, facilitando el proceso de aprendizaje y memoria. Si bien la organización del recuerdo puede estar facilitada, carecerá de los temas / ideas principales que caracterizan al lived-throughness. Por otro lado, en cuanto a las diferencias asociadas al factor ideológico, se puede conjeturar que habría temas / ideas principales específicos promovidos por la ideología. Es esperable que el grupo ideológico de Derecha manifieste en su recuerdo una mayor proporción de temas / ideas principales como, por ejemplo, las víctimas provocadas por grupos como el ERP o Montoneros, mientras que estas víctimas, si bien pueden ser recordadas por el grupo ideológico de Izquierda, se presentarían en este grupo en una proporción significativamente menor que otros temas / ideas principales. Será interesante observar cuáles son los temas / ideas principales que tiende a promover la ideología política de los participantes.

Si bien estudios previos muestran que hay diferencias entre los distintos tipos de memoria colectiva, no permiten anticipar cómo estas diferencias operarán sobre la dimensión del recuerdo que interesa para esta investigación. Por otro lado, por operar como un esquema, las diferencias y similitudes por ideología son más esperables y capaces de precisar. Por todo ello es que sin más predicciones que las men- 
cionadas se solicitó a los participantes que completaran una Prueba de Recuerdo Libre. Se exploraron, entonces, las diferencias y similitudes en el recuerdo producido en torno a los hechos del Golpe de Estado de 1976, atendiendo a los niveles de proporción que ocupan los temas o ideas principales en la producción de los participantes de cada generación y de cada grupo ideológico.

\section{MÉTodo}

\section{MUESTRA}

La muestra estuvo integrada por 52 sujetos, 32 mujeres $(61.5 \%)$ y 20 hombres $(38.5 \%)$. La media de edad fue igual a 39 años (rango 1967 años). Todos los participantes eran argentinos. Participaron estudiantes de la Universidad de Belgrano a cambio de créditos académicos, empleados de la Universidad y otros voluntarios que accedieron a participar de un estudio de memoria a cambio de un pago de $\$ 50$ y fueron contactados mediante anuncios en las carteleras de diversas facultades de la universidad. Los otros participantes fueron referidos por los asistentes que colaboraron en la investigación.

Se conformaron dos grupos, por un lado, aquellos mayores de 48 años, cuyos recuerdos del golpe eran de tipo semántico vivido, y por otro, los menores de 30 , cuyos recuerdos del golpe eran de tipo semántico distante. La mitad de los participantes con recuerdos distantes fueron alumnos de la Universidad de Belgrano. En cuanto a los participantes con recuerdos vividos, 12 eran empleados de la Universidad y 18 eran personas ajenas a la misma. El 90\% tenía, al menos, escolaridad secundaria completa.

Con respecto a la ideología, 16 sujetos se definieron con una orientación política de Derecha, 21 lo hicieron con una de Izquierda y 15 se definieron como perteneciendo al Centro. La categoría Centro es aceptable al pensar el arco ideológico, pero serían Derecha e Izquierda los organizadores del mismo (Bobbio, 1996), en tanto y en cuanto los que se definieron como de Centro terminan inclinán- dose hacia la Derecha o hacia la Izquierda. En función de esto último, se recategorizó el grupo de Centro en Derecha o Izquierda. Para ello, dos asistentes de investigación se basaron tanto en el reporte del político como del partido político con los cuales el participante en cuestión refirió sentirse más identificado. Por ejemplo, si el participante indicó como ideología política el Centro, pero se identifica con Mauricio Macri y su partido político es Propuesta Republicana (PRO), se lo reclasificó como de Derecha. En la reclasificación hubo cuatro desacuerdos, tres de los cuales fueron resueltos en una discusión entre los asistentes a cargo de la reclasificación. El protocolo restante fue eliminado. De esta manera, la muestra final estuvo compuesta de 52 sujetos, 26 (Grupo Derecha) y 26 (Grupo Izquierda). Cada grupo ideológico estuvo compuesto por 13 con memorias colectivas semánticas de tipo vivido y 13 con memorias colectivas semánticas de tipo distante. Las medias y rangos de edad para cada grupo fueron los siguientes: MCSV - Derecha (53 años: 48-66); MCSV - Izquierda (56 años: 48-67), MCSD - Derecha (24 años: 19-30), MCSD Izquierda (25 años: 19-30).

\section{INSTRUMENTOS}

Se elaboró un cuestionario compuesto por dos secciones: la primera indaga sobre datos demográficos, edad, sexo, educación e ideología política, el partido político (por ejemplo, Unión Cívica Radical, Peronismo, Frente para la Victoria, Propuesta Republicana -PRO-, etc.) y por la persona política con la que más se identifican (por ejemplo, Kirchner, Alfonsín, Menem, Solanas, Carrió, Macri, etc.). En el caso de nivel educativo e ideología política se ofrecen distintas opciones de respuesta: Estudios Primarios Completos, Estudios Secundarios Completos, Estudios Terciarios Completos o Estudios Universitarios Completos, para nivel educativo, y Derecha, Centro o Izquierda, para ideología política.

En la segunda sección se solicita que realicen una Prueba de Recuerdo Libre. Los par- 
ticipantes recibieron una hoja con la siguiente consigna: "En la presente hoja, escriba todo lo que usted sepa sobre los acontecimientos del 24 de marzo de 1976 (día del último golpe de Estado y del comienzo de la última dictadura militar), así como de los acontecimientos previos y posteriores vinculados a esa fecha".

\section{Procedimiento}

Los participantes brindaron su consentimiento y posteriormente recibieron una versión impresa del protocolo para que lo completaran. Un asistente estuvo presente para responder las dudas u otras dificultades que pudieran surgir durante la prueba. Los alumnos y empleados de la Universidad de Belgrano la realizaron en las oficinas del Departamento de Investigaciones. El resto lo hizo en sus domicilios.

\section{ANÁLISIS DE LOS DATOS}

Para el análisis de la Prueba de Recuerdo Libre, se siguió en líneas generales la clasificación de van Dijk $(2003,2005,2008)$ sobre el discurso. Específicamente, se analizaron los temas e ideas principales presentes en el recuerdo de cada participante, según los criterios especificados previamente.

Los protocolos fueron analizados en términos de las posibles categorías que dieran cuenta de los temas / ideas principales que estaban presentes en el recuerdo. Como no existían predicciones a priori sobre las posibles categorías en las que serían agrupadas las respuestas, dos asistentes distintos a los autores clasificaron las respuestas de los participantes. Hubo un $81 \%$ de acuerdo inicial en las categorías conformadas. Las diferencias se discutieron hasta lograr un acuerdo sobre el total de las categorías a utilizarse. Se conformó así un total de 58 categorías de temas / ideas principales (ver Anexo 1).

El criterio utilizado para la conformación de las categorías fue que dos o más respuestas fueran clasificadas en la misma categoría si implicaban el mismo concepto o evento, es decir si tenían el mismo contenido. El principio que guió a la clasificación fue el de agrupar respuestas si su contenido podía ser descripto por una misma categoría (por ejemplo, la expresión golpe cívico-militar y otras expresiones que reflejaran el apoyo de sectores ciudadanos al golpe fueron agrupadas bajo la categoría Apoyo civil al golpe). Ahora bien, si una respuesta aportaba una nueva información que permitiera un análisis más detallado, se creaba una nueva categoría. Por ejemplo, las afirmaciones muy generales sobre violaciones a los derechos humanos constituyeron una categoría separada, pero las referencias a Torturas o Asesinatos dieron lugar a la creación de esas categorías más específicas.

Finalmente, otros dos asistentes de investigación distintos a los anteriores, utilizando las categorías ya conformadas, leyeron cada protocolo y clasificaron las respuestas según las categorías de la grilla conformada previamente. Tuvieron un $85 \%$ de acuerdo. Todas las discrepancias fueron resueltas.

Para la operacionalización de los temas / ideas principales en términos de proporción para su posterior análisis estadístico, se realizó el siguiente procedimiento: al total de las respuestas de un sujeto se le asignó el valor 1, luego se dividió este valor por la cantidad de temas / ideas principales mencionados por dicho sujeto, y el porcentaje resultante es la proporción de cada tema / idea principal específico para dicho participante. Por ejemplo, si un participante recordó 4 temas / ideas principales, a cada uno de ellos se le asignó el valor .25

Se realizó un ANOVA bifactorial intersujetos, considerando como factores o variables independientes al tipo de recuerdo colectivo (Memoria Colectiva Semántica Vivida -MCSV- vs. Memoria Colectiva Semántica Distante -MCSD-) y al grupo ideológico (Grupo de Derecha vs. Grupo de Izquierda). Por lo tanto, el diseño del análisis es $2 \times 2$. Los temas / ideas principales conformaron la variable dependiente. Se analizó la variación en las proporciones que ocupan los temas / ideas principales según cada factor de estudio. Se reporta en primer lugar, el tipo de re- 
cuerdo, luego la ideología y finalmente las interacciones.

\section{Resultados}

\section{TIPO DE RECUERDO}

Los resultados se presentan en función de los temas / ideas principales que ocuparon un mayor lugar en el recuerdo de la generación mayor, que contribuye a la memoria colectiva semántica vivida, y de la generación menor, que contribuye a la memoria colectiva semántica distante. Hay 8 temas / ideas principales que tuvieron mayor presencia en el recuerdo de la generación menor en comparación con la mayor y 4 que fueron más relevantes en el recuerdo de la generación mayor cuando se los compara con el recuerdo de la generación menor. En la Tabla 1 se presentan las medias de proporción y las desviaciones estándar de mención de categorías, según tipo de recuerdo y grupo ideológico.

En cuanto a la generación mayor, el tema Cierre de facultades públicas e instituciones educativas mostró un efecto principal $[F(1$, $\left.48)=5.222, p=.027, n_{\mathrm{p}}{ }^{2}=.098\right]$, en donde los participantes con MCSV le otorgaron una proporción mayor en su recuerdo $(M=.05$, $D E=.11)$ que aquellos con $\operatorname{MCSD}(M=.00$, $D E=.02)$, siendo esta diferencia estadísticamente significativa.

Otro efecto principal fue para el tema Expectativa con la llegada de los militares $[F(1$, $\left.48)=4.854, p=.032, n_{\mathrm{p}}{ }^{2}=.092\right]$. Este tema ocupó también una proporción significativamente superior en el recuerdo de los participantes con $\operatorname{MCSV}(M=.10, D E=.22)$ que en el recuerdo de los participantes con MCSD $(M=.00, D E=.02)$.

Se encontró también un efecto principal para el tema Violencia política de grupos de izquierda (previa al golpe) $[F(1,48)=6.467$, $\left.p=.014, n_{\mathrm{p}}{ }^{2}=.119\right]$. Aquellos de la generación mayor, con $\operatorname{MCSV}(M=.06, D E=.10)$, lo recordaron en una proporción significativamente mayor que aquellos de la generación menor, con $\operatorname{MCSD}(M=.01, D E=.03)$.
Otro tema que mostró diferencias en función del tipo de recuerdo fue Crisis económica previa al golpe $[F(1,48)=4.478$, $\left.p=.040, n_{\mathrm{p}}{ }^{2}=.085\right]$. Los participantes con $\operatorname{MCSV}(M \underline{\underline{p}} .06, D E=.10)$ mostraron que este tema ocupaba una proporción significativamente mayor en su recuerdo que en los participantes con $\operatorname{MCSD}(M=.01, D E=.03)$.

Con respecto a la generación menor, se encontró un efecto principal del tipo de recuerdo para el tema Régimen militar $[F(1$, $\left.48)=8.484, p=.005, n_{\mathrm{p}}{ }^{2}=.150\right]$. Para las personas con $\operatorname{MCSD}(M \underline{\underline{\mathrm{p}}} .09, D E=.06)$ este tema ocupó una proporción significativamente superior en sus recuerdos del golpe que en los de los participantes con MCSV $(M=.04, D E=.07)$.

Asimismo, se encontró un efecto principal para el tema Desaparecidos $[F(1,48)=11.888$, $\left.p=.001, n_{\mathrm{p}}{ }^{2}=.199\right]$. Los participantes con $\operatorname{MCSD}(M=.09, D E=.10)$ le otorgaron una mayor proporción en sus recuerdos que aquellos con MCSV $(M=.02, D E=.04)$, siendo esta diferencia significativa.

Otro tema que reflejó diferencias entre los grupos fue Represión $[F(1,48)=6.737$, $\left.p=.012, n_{\mathrm{p}}{ }^{2}=.123\right]$. El grupo con MCSD le otorgó una presencia significativamente mayor a este tema $(M=.03, D E=.05)$ que el grupo de $\operatorname{MCSV}(M=.00, D E=.00)$.

También varió en función del tipo de recuerdo el tema Asesinatos cometidos por la dictadura $[F(1,48)=10.459, p=.002$, $\left.n_{\mathrm{p}}{ }^{2}=.179\right]$. También en este caso fueron los participantes con $\operatorname{MCSD}(M=.03, D E=.04)$ quienes le otorgaron una mayor proporción en sus recuerdos que aquellos participantes con $\operatorname{MCSV}(M=.00, D E=.01)$. Esta diferencia también fue significativa.

El tema Otras violaciones a los derechos humanos mostró también un efecto principal $\left[F(1,48)=4.615, p=.037, n_{\mathrm{p}}{ }^{2}=.088\right]$. Los sujetos con MCSD $(M=.02, D E=.03)$ lo mencionaron en mayor medida que aquellos con $\operatorname{MCSV}(M=.00, D E=.01)$. Esta diferencia fue estadísticamente significativa. 
También se encontraron diferencias significativas en función del tipo de recuerdo para el tema Actos terroristas $[F(1,48)=4.840$, $\left.p=.033, n_{\mathrm{p}}{ }^{2}=.092\right]$. Los participantes de la generación menor -MCSD- $(M=.02$, $D E=.05)$ le dieron una mayor presencia en su recuerdo del golpe que aquellos participantes de la generación mayor -MCSV- $(M=.00$, $D E=.00)$.

La Participación de Estados Unidos en el golpe de Estado fue otro tema en el que se encontró un efecto principal para tipo de recuerdo $[F(1,48)=4.234, p=.045$, $\left.n_{\mathrm{p}}{ }^{2}=.081\right]$. En este caso, aquellos de la generación menor -MCSD- $(M=.01, D E=.03)$ recordaron este tema en una proporción significativamente superior que aquellos participantes de la generación mayor -MCSV$(M=.00, D E=.00)$.

Un último tema que fue afectado por el tipo de recuerdo es Juicios y condenas a los militares $[F(1,48)=4.518, p=.039$, $\left.n_{\mathrm{p}}{ }^{2}=.086\right]$. En este caso, aquellos con $\operatorname{MCSD}(M=.02, D E=.04)$ lo mencionaron en mayor proporción que aquellos con $\operatorname{MCSV}(M=.00, D E=.00)$.

\section{IDEOLOGÍA}

También el factor Ideología tuvo incidencia en los temas / ideas principales recordados por los participantes. Nuevamente, los resultados se presentan en función de los temas / ideas principales que ocuparon un mayor lugar en el recuerdo de cada grupo ideológico. De todos modos, en este caso, en todos los temas / ideas principales en los cuales se encontró un efecto principal, se debió al mayor lugar que ocupaban estos temas / ideas principales en el recuerdo del grupo ideológico de Izquierda cuando se los comparaba con el lugar que tenían en el grupo ideológico de Derecha (ver Tabla 1).

Dentro de los temas que arrojaron diferencias significativas entre los grupos se encuentra la Apropiación de bebés. Este ocupó una proporción mayor en el recuerdo del grupo ideológico de Izquierda $(M=.02$, $D E=.03$ ) que la proporción que ocupó en el recuerdo del grupo ideológico de Derecha $(M=.00, D E=.00)$, siendo esta diferencia estadísticamente significativa $[F(1,48)=6.695$, $\left.p=.013, n_{\mathrm{p}}{ }^{2}=.122\right]$.

Asimismo el Mundial '78 y su utilización fue recordado por el grupo ideológico de Izquierda $(M=.01, D E=.03)$ en mayor proporción que el grupo ideológico de Derecha $(M=.00, D E=.00)$, siendo esta diferencia significativa $[F(1,48)=4.904, p=.032$, $\left.n_{\mathrm{p}}{ }^{2}=.093\right]$.

Otro tema propio del grupo ideológico de Izquierda $(M=.01, D E=.03)$ fue la Participación de Estados Unidos en el golpe de Estado, en cuyo recuerdo ocupó una mayor proporción que en el recuerdo del grupo ideológico de Derecha $(M=.00, D E=.00)$, siendo esta diferencia significativa $[F(1$, 48) $\left.=4.234, p=.045, n_{\mathrm{p}}{ }^{2}=.081\right]$.

También el tema Muerte de Perón mostró un efecto principal $[F(1,48)=9.353$, $\left.p=.004, n_{\mathrm{p}}{ }^{2}=.163\right]$. Los participantes de Izquierda $(M=.06, D E=.07)$ lo recordaron en mayor medida que los participantes de Derecha $(M=.01, D E=.03)$.

Otro tema que recibió un mayor lugar en el recuerdo colectivo del golpe por parte de los participantes del grupo ideológico de Izquierda fue la Violencia política de grupos de Derecha (previa al golpe). Se encontró un efecto principal $[F(1,48)=6.275, p=.016$, $\left.n_{\mathrm{p}}{ }^{2}=.116\right]$. Aquellas personas del grupo ideológico de Izquierda $(M=.03, D E=.04)$ lo mencionaron en mayor proporción que los del grupo de Derecha $(M=.00, D E=.02)$.

Un último tema en el cual se encontró un efecto principal fue la Asunción de Alfonsín y retorno de la democracia $[F(1,48)=4.099$, $\left.p=.048, n_{\mathrm{p}}{ }^{2}=.079\right]$. Los miembros del grupo ideológico de Izquierda $(M=.03, D E=.04)$ lo incluyeron en su recuerdo en mayor proporción que los del grupo de Derecha $(M=.01$, $D E=.03)$, siendo esta diferencia significativa. 


\section{INTERACCIÓN}

Se produce una interacción de los dos factores estudiados en tres temas / ideas principales (ver Tabla 1). El tema Argumentos de los militares para justificar el golpe mostró un efecto significativo de interacción entre ambos factores $[F(1,48)=6,670, p=.013$, $\left.n_{\mathrm{p}}{ }^{2}=.122\right]$. Los participantes con MCSD pertenecientes al grupo de Izquierda recordaron este tema en mayor proporción que aquellos con MCSD y del grupo de Derecha $[t(24)=-3.20, p<.005]$. Por otro lado, no hubo diferencias significativas entre participantes de los grupos de Derecha e Izquierda con $\operatorname{MCSV}[t(24)=.792, p=.436]$.

Un segundo tema que mostró un efecto de interacción entre ambos factores fue Participación de Estados Unidos en el golpe de Estado $\left[F(1,48)=4.234, p=.045, n_{\mathrm{p}}{ }^{2}=.081\right]$. En este caso, aquellos con MCSD pertenecientes al grupo de Izquierda mostraron una tendencia a mencionar este tema en mayor proporción que aquellos con MCSD y del grupo de Derecha, si bien no de forma significativa $[t(24)=-2.05, p=.051]$. Ninguno de los participantes con MCSV incluyó este tema / idea principal en su recuerdo.

Por último, se encontró un efecto de interacción para el tema Muerte de Perón $\left[F=(1,48)=4.483, p=.039, n_{\mathrm{p}}{ }^{2}=.085\right]$. En este caso, aquellos participantes con MCSV y del grupo de Izquierda le brindaron un mayor lugar en su recuerdo que los participantes con MCSV y del grupo de Derecha $[t(24)=-3.05, p<.01]$. Por otro lado, no hubo diferencias significativas entre participantes de los grupos de Derecha e Izquierda con $\operatorname{MCSD}[t(24)=-.883, p=.386]$.

\section{SIMILITUDES}

Si bien se encontraron diferencias entre los grupos, hay que destacar también la gran cantidad de temas / ideas principales en los cuales no se encontraron diferencias significativas. En total, se encontraron diferencias en 18 de las 58 categorías que conforman los temas / ideas principales. Esto quiere decir que hay un $68.96 \%$ de los temas / ideas principales en los que no hay diferencias considerando el tipo de recuerdo y la ideología política.

Considerando los temas / ideas principales según el tipo de recuerdo, se encontraron diferencias significativas para 12 de los 58 . Esto quiere decir que no hay diferencias según el tipo de recuerdo en el $79.31 \%$. Una mayoría de los temas / ideas principales comparten igual proporción en la memoria colectiva del golpe, ya sea que se trate de memoria colectivas semánticas vividas o de memorias colectivas semánticas distantes.

Por otro lado, al considerar los temas / ideas principales de mayor relevancia según la ideología, se encuentra que solamente 6 de los 58 muestran una diferencia de proporción. El 89.66\% muestra igual grado de presencia en el recuerdo para ambos grupos ideológicos. Por último, al considerar los efectos de interacción entre el tipo de recuerdo y la ideología, se observa que sólo se produjeron para 3 de las 58 categorías. Es decir, para el $94.83 \%$ de las categorías no hubo efectos de interacción.

\section{Discusión}

Se establecieron dos objetivos para esta investigación: contribuir al campo en desarrollo de una psicología de la memoria colectiva, al tiempo de estudiar específicamente la memoria colectiva del Golpe de Estado de 1976.

En primer lugar, se discutirán los resultados considerando los temas / ideas principales, en sus similitudes y diferencias, que conforman la memoria colectiva del golpe. En segundo lugar, se desarrollarán las implicancias de estos hallazgos para el estudio de la memoria colectiva desde una perspectiva psicológica.

Un primer hallazgo a destacar es la significativa similitud que se encontró en el recuerdo de los distintos grupos, como se re- 
fleja en la falta de diferencias para la mayoría de los temas / ideas principales recordados. Si bien se encontraron diferencias en función de la generación y de la ideología política de los participantes en los recuerdos del golpe, es necesario destacar esta ausencia de diferencias en la mayoría de las categorías que conformaron los temas / ideas principales. Esta estabilidad es la que Wertsch (2002) describe cuando habla de la universalidad de las plantillas narrativas esquemáticas (schematic narrative templates) de la memoria colectiva nacional. Considerando el conjunto de categorías en las cuales no se encontraron diferencias significativas, se puede comenzar a elaborar una matriz de la memoria nacional, incluyendo el conjunto de temas / ideas principales en los que no se encontraron diferencias por generaciones ni por ideologías.

Como ya se mencionó, no se encontraron diferencias por tipo de recuerdo para 46 temas/ ideas principales, ni por ideología para 52 de estas mismas categorías. Si se toman los 29 de mayor frecuencia (la mitad superior en frecuencias de mención del total de categorías que conforman el Anexo 1), los participantes de ambas generaciones, ya sean del grupo ideológico de Izquierda o de Derecha, recuerdan en igual proporción temas / ideas principales tales como Terrorismo de Estado, Privación de libertades, Persecuciones, Torturas, Guerra de Malvinas y sus usos, Apoyo civil al golpe (por ej., el golpe cívico-militar), Argumentos para justificar el golpe, Desarrollo de guerra entre dos grupos, Políticas económicas del gobierno militar, Crecimiento de la deuda pública, Crisis política previa al golpe, Violencia entre derecha e izquierda previa al golpe, Poder desmesurado de López Rega y Disconformidad social con el gobierno de Isabel Perón.

De esta manera, considerando estas similitudes de temas / ideas principales, se pueden conformar los elementos de una matriz primaria o plantilla de la memoria colectiva que los argentinos tienen del golpe de 1976. Así, una memoria tipo podría describirse de la siguiente manera:

En un contexto de violencia entre grupos de derecha y de izquierda y de una importante crisis política del gobierno de Isabel Perón, sobre el cual recaía una gran disconformidad social y en el que López Rega tenía un poder desmesurado, el 24 de marzo de 1976, una Junta Militar derrocó a Isabel Perón, con el apoyo de un sector de la sociedad. Los militares argumentaron que iban a instaurar el orden. Sin embargo, implantaron el terrorismo de Estado, persiguieron, torturaron y privaron de libertades al pueblo argentino. El contexto general es de una guerra entre dos facciones. En el aspecto económico, llevaron adelante un modelo neoliberal y generaron un crecimiento de la deuda pública. Sobre el final de la dictadura, los militares iniciaron la Guerra de Malvinas, con la cual esperaban distraer sobre los crímenes cometidos y perpetuarse en el poder.

Así, se encuentran una serie de elementos en común entre las distintas personas, más allá de su ideología o del tipo de recuerdo del que disponen, entre los que se pueden destacar: (1) hechos ocurridos entre 1976 y 1983, tales como las violaciones a los Derechos Humanos por parte de la dictadura y otros actos del gobierno militar, como el incremento de la deuda pública o la utilización de la Guerra de Malvinas, así como la presencia de una guerra o conflicto entre dos grupos o facciones, (2) algunos aspectos contextuales, como la responsabilidad de López Rega en los hechos de violencia previos al golpe de Estado, la debilidad del gobierno de Isabel Perón, el apoyo de ciertos sectores de la sociedad al golpe (Apoyo civil al golpe incluyó las menciones a conductas y no a estados emocionales) o la violencia entre derecha e izquierda en la década de los años 70.

Por otro lado, el estudio evidencia que hay temas / ideas principales que son más promovidos por una u otra generación al considerar la distinción entre memoria colectiva semántica vivida y memoria colectiva semántica distante. Por ejemplo, el estudio muestra que la memoria colectiva de los argentinos va a incluir en mayor grado entre sus temas / ideas principales el Cierre de facultades públicas e instituciones educativas, la Expectativa con la llegada de los militares, la Violencia política de grupos de Izquierda (previa al golpe), así como la crisis económica previa al golpe, si 
los que recuerdan son personas de la generación mayor (MCSV). En contraste, aquellos de la generación menor (MCSD) enfatizan temas / ideas principales vinculados a las violaciones a los Derechos Humanos por parte de la dictadura, tales como Desaparecidos, Represión o Asesinatos, como así también crímenes de organizaciones guerrilleras (Actos terroristas) y hechos que tuvieron lugar después de la dictadura (Juicios y condenas a militares).

Cuando se atiende a la ideología política de las personas que recuerdan el golpe, se encuentra que también tiene incidencia en lo recordado. Las personas del grupo ideológico de Izquierda tienden a promover en su recuerdo, en mayor medida que las personas del grupo ideológico de Derecha, los siguientes temas / ideas principales: Apropiación de bebés, Mundial 78 y su utilización, Participación de Estados Unidos en el golpe, Muerte de Perón, Violencia política de grupos de Derecha previa al golpe y Asunción de Alfonsín y retorno de la democracia. De manera interesante, no hubo algún tema / idea principal que fuera promovido en mayor medida por el grupo ideológico de Derecha.

Las interacciones entre el tipo de recuerdo y la ideología fueron escasas. Se encontró una interacción para tres temas / ideas principales. En dos casos (Argumentos de los militares para justificar el golpe y Participación de Estados Unidos en el golpe de Estado) las interacciones fueron entre las MCSD y el grupo ideológico de Izquierda y en otro (Muerte de Perón) entre la MCSV y el grupo de Izquierda.

Si bien hasta aquí los resultados aportan valiosa información sobre distintos contenidos de la memoria colectiva del golpe de Estado de 1976, ¿qué nos enseñan estos datos sobre la memoria colectiva? Como mostraron Manzi y colaboradores (2004), hay elementos de la memoria colectiva que parecen no variar en función del grupo que recuerda. Por ejemplo, en su estudio, las personas de Centro-Izquierda y las de Derecha recordaron los mismos hechos, pero las diferencias estuvieron en lo que consideraron como las causas y las consecuencias del golpe en Chile.
Los resultados muestran que la generación mayor (MCSV) tiende a diferenciarse de la menor (MCSD) en tanto que tiende a promover, dentro del recuerdo, aspectos contextuales y de tipo emocional / afectivo. Por ejemplo, la Expectativa con la llegada de los militares, que incluyó las referencias a estados emocionales positivos de los ciudadanos ante el golpe de Estado (por ej., esperanza de orden, conformidad) y la Violencia de grupos de Izquierda previa al golpe y la Crisis económica previa al golpe, que son temas / ideas principales que hacen referencia al contexto, son más promovidos por los participantes que han vivido los hechos (lived-throughness). Los elementos del contexto y del humor social permiten conectar los hechos entre sí, otorgándoles a los recuerdos una mayor elaboración. Otro tema / idea principal destacado por la generación mayor, el Cierre de facultades públicas e instituciones educativas, muestra que entre los temas / ideas principales recordados se promueven en mayor medida aquellos hechos que pudieron afectar directamente la vida cotidiana.

Por otro lado, el recuerdo colectivo de la generación menor presenta dos características. Primero, enfatiza cierta cantidad de hechos acontecidos y promueve un recuerdo que se caracteriza por la enumeración de los hechos más salientes. Segundo, incluye temas / ideas principales que tienen relevancia en el presente. Por ejemplo, entre los hechos, los Asesinatos, la Represión y las Desapariciones recuerdan los delitos que cometieron los militares, mientras que los Juicios y condenas a los militares es un tema / idea principal que aún tienen relevancia en el presente, ya que en Argentina continúan desarrollándose los juicios a los responsables de los crímenes cometidos en aquellos años.

La ideología parece ser también un factor central a la hora de estudiar la memoria del golpe. Los resultados obtenidos muestran que las personas del grupo ideológico de Izquierda dan importancia en su recuerdo a una serie de temas / ideas principales que aparecen como irrelevantes en el grupo de Derecha.

Las personas con una ideología de Izquierda resaltan cuestiones que parecen con- 
sistentes con su esquema, como por ejemplo, la Violencia de grupos de Derecha previa al golpe. Algo similar parece tener lugar con la Apropiación de bebés y la Participación de Estados Unidos en el golpe, ya sea porque destaca los crímenes de una dictadura de Derecha o bien porque enfatiza el rol de Estados Unidos, habitualmente mencionado como un impulsor de dictaduras de Derecha en América Latina en esa época. Otra contribución que surge de considerar a la ideología como factor en el estudio de la memoria colectiva es que el grupo ideológico de Izquierda tiende a promover en su recuerdo temas / ideas principales que ofrecen una contextualización de los hechos recordados, como por ejemplo, la Asunción de Alfonsín y retorno de la democracia, la Muerte de Perón y la Participación de Estados Unidos en el golpe.

En cuanto a las interacciones significativas encontradas, el recuerdo de la Muerte de Perón por los participantes con MCSV y del grupo de Izquierda era esperable dado que ambos grupos enfatizaron los aspectos contextuales del golpe. De todos modos, para la Muerte de Perón sólo se encontraron efectos principales por Ideología, por lo que la interacción podría vincularse también con que para la generación mayor de Izquierda, probablemente con cierto grado de involucramiento político durante aquellos años, la muerte del ex presidente podría haber sido un factor muy vinculado al golpe de Estado posterior. Con respecto al recuerdo de los Argumentos de los militares para justificar el golpe y de la Participación de Estados Unidos en el golpe de los participantes con MCSD y del grupo de Izquierda, se considera que se debería a que ambos son temas que suelen destacarse en las narrativas que conforman las fuentes indirectas (como por ejemplo, manuales de Historia, documentales, etc.), que suelen destacar los actores principales y los argumentos utilizados por los mismos. Estas fuentes indirectas son, a la vez, la fuente principal de conocimiento de los hechos para aquellos que no vivieron durante los años de la dictadura (MCSD). Ciertamente, el hecho de destacar los Argumentos de los militares para justificar el golpe, podría resultar más re- levante para un miembro de Izquierda de la generación menor que para uno de Derecha. Además, para el caso de la Participación de Estados Unidos en el golpe, se debe tener en cuenta lo ya mencionado, sobre el énfasis de los participantes de Izquierda en los aspectos contextuales. Finalmente, destacar el rol de Estados Unidos en el golpe resulta consistente con un esquema ideológico orientado a la Izquierda.

Se ha postulado en otro trabajo (Muller et al., 2015) que así como se puede pensar la memoria autobiográfica en términos de un sistema de memoria personal (Conway \& Pleydell-Pearce, 2000) que orienta el recuerdo según metas y objetivos, habría también un sistema de la 'memoria nacional', que regula el proceso de recuerdos del pasado. Esta regulación tendría lugar activando estructuras de conocimiento, tomando ciertos indicios y finalmente construyendo recuerdos específicos. Si bien este sistema de memoria lo poseen individualmente los ciudadanos de una nación, está extendido entre estos y se mantiene estable en el tiempo. Esto daría cuenta de los aspectos comunes del recuerdo.

Pero también los grupos, ya sea el de las generaciones mayores o menores, o los de izquierda o derecha, tienen sus propias metas y objetivos cuando recuerdan. Se ha comenzado a identificar de qué manera contribuyen a la memoria colectiva tanto las generaciones con distintos tipos de recuerdos, como la ideología política, mediante el estudio del contenido del recuerdo del golpe de 1976. Se encuentra que hay una mayoría de temas / ideas principales que son comunes a todos los grupos y que también hay temas / ideas principales específicos que son promovidos por los distintos grupos estudiados, y es ahí donde las metas y objetivos de estos grupos empiezan a intervenir sobre este sistema de memoria nacional.

van Dijk (2003) sostiene que la ideología de las personas y los grupos, tal como se manifiesta en el discurso, tiende a enfatizar los aspectos positivos del propio grupo y los negativos de otros grupos, a la vez que busca restar énfasis a los aspectos positivos de otros grupos y a los aspectos negativos del propio 
grupo. Baumeister y Hastings (1998) a su vez, plantean que los individuos y grupos intentan mantener una imagen positiva de sí mismos. Si se consideran, además, para el campo específico de la memoria las ideas de Conway (1998), quien afirma que la memoria semántica y el conocimiento conceptual pueden ser moldeados por planes y metas, y que es en dicho tipo de memoria donde se harían evidentes diferencias marcadas entre las cohortes generacionales, se puede pensar que el recuerdo de los participantes de nuestro estudio también estaría al servicio del cumplimiento de metas individuales y / o grupales, tales como la cohesión intragrupal o el mantenimiento de una identidad positiva. Pero este es un aspecto que no ha sido explorado en el estudio realizado.

Hay otros dos aspectos que tampoco se atendieron en este estudio y constituyen puntos de partida para futuras investigaciones: el nivel de participación política real de los su- jetos, que puede moderar la influencia de la ideología en el recuerdo, y no haber diferenciado, dentro de la generación mayor, entre las personas que han sido víctimas directas del terrorismo de Estado de las que no lo han sido. Además, entre las limitaciones de este estudio, se debe mencionar también el incremento de la posibilidad de error de tipo I, debido a los múltiples análisis llevados a cabo, así como la limitación propia de haber utilizado un muestreo no probabilístico (muestreo de tipo intencional).

Las preguntas en torno a cómo afectan la memoria colectiva los objetivos de los grupos, el nivel de participación política de sus miembros y la distinción entre víctimas directas e indirectas del terrorismo de Estado, constituyen un punto de partida para futuros estudios sobre la memoria colectiva, las generaciones, la ideología y los factores motivacionales. 
TABLA 1

MEDIAS DE PROPORCIÓN DE TEMAS / IDEAS PRINCIPALES EN FUNCIÓN DEL TIPO DE RECUERDO Y DE LA IDEOLOGÍA

\begin{tabular}{|l|cc|cc|}
\hline \multicolumn{1}{|c|}{ Temas / Ideas principales } & Memorias Semánticas Vividas & \multicolumn{2}{l}{ Memorias Semánticas Distantes } \\
& Izquierda & Derecha & Izquierda & Derecha \\
& $M(D E)$ & $M(D E)$ & $M(D E)$ & $M(D E)$ \\
\hline Régimen militar & & & & \\
Desaparecidos & $.03(.05)$ & $.06(.08)$ & $.08(.04)$ & $.11(.07)$ \\
Represión & $.02(.03)$ & $.02(.05)$ & $.06(.04)$ & $.12(.14)$ \\
Asesinatos cometidos por la dictadura & $.00(.00)$ & $.00(.00)$ & $.03(.04)$ & $.03(.06)$ \\
Cierre de facultades & $.00(.01)$ & $.00(.00)$ & $.03(.04)$ & $.02(.05)$ \\
Otras violaciones a los Derechos Humanos & $.08(.13)$ & $.03(.09)$ & $.01(.02)$ & $.00(.00)$ \\
Expectativa con la llegada de los militares & $.00(.01)$ & $.00(.00)$ & $.02(.03)$ & $.01(.03)$ \\
Actos terroristas & $.03(.07)$ & $.16(.29)$ & $.00(.00)$ & $.01(.02)$ \\
Participación de Estados Unidos & $.00(.00)$ & $.00(.00)$ & $.01(.03)$ & $.03(.07)$ \\
Violencia previa de grupos de Izquierda & $.00(.00)$ & $.00(.00)$ & $.02(.04)$ & $.00(.00)$ \\
Crisis económica previa al golpe & $.03(.05)$ & $.09(.12)$ & $.01(.03)$ & $.01(.04)$ \\
Juicios y condenas a los militares & $.06(.11)$ & $.05(.08)$ & $.02(.03)$ & $.01(.04)$ \\
Apropiación de bebés & $.00(.00)$ & $.00(.00)$ & $.01(.02)$ & $.03(.05)$ \\
Mundial '78 y su utilización & $.00(.02)$ & $.00(.00)$ & $.03(.04)$ & $.00(.00)$ \\
Muerte de Perón & $.01(.02)$ & $.00(.00)$ & $.02(.04)$ & $.00(.00)$ \\
Violencia previa de grupos de Derecha & $.08(.09)$ & $.01(.02)$ & $.03(.04)$ & $.02(.04)$ \\
Retorno de la democracia (Alfonsín) & $.04(.05)$ & $.01(.03)$ & $.02(.03)$ & $.00(.00)$ \\
Argumentos de los militares & $.01(.02)$ & $.01(.03)$ & $.04(.05)$ & $.01(.02)$ \\
& $.01(.03)$ & $.02(.05)$ & $.04(.05)$ & $.00(.00)$ \\
\hline
\end{tabular}




\section{ANEXO 1}

Categorías de Temas / IdeAs PRINCIPALES, POR ORDEN DECRECIENTE DE FRECUENCIAS DE MENCIÓN

\begin{tabular}{|c|c|}
\hline Temas / Ideas principales & Frecuencia \\
\hline Golpe de Estado & 36 \\
\hline Régimen militar (políticas y características del gobierno) & 32 \\
\hline Desaparecidos & 24 \\
\hline Violencia entre Derecha e Izquierda previa al golpe & 17 \\
\hline Muerte de Perón & 17 \\
\hline Restricción / Privación de libertades individuales & 15 \\
\hline Violencia política de grupos de Izquierda (previa al golpe) & 14 \\
\hline Crisis económica previa al golpe & 14 \\
\hline Guerra de Malvinas (uso y consecuencias) & 14 \\
\hline Disconformidad social con el gobierno de Isabel Perón & 12 \\
\hline Asesinatos & 11 \\
\hline Asunción de Alfonsín y retorno de la democracia & 11 \\
\hline Terrorismo de Estado & 10 \\
\hline Apoyo civil al golpe (por ej., golpe cívico-militar) & 10 \\
\hline Violencia política de grupos de Derecha (previa al golpe) & 10 \\
\hline Argumentos de los militares para justificar el golpe & 10 \\
\hline Cuestiones sociales / políticas / económicas previas al golpe & 9 \\
\hline Torturas & 9 \\
\hline Expectativa con la llegada de los militares & 9 \\
\hline Crecimiento de la deuda pública & 8 \\
\hline Represión & 7 \\
\hline Cierre de facultades públicas e instituciones educativas & 7 \\
\hline Políticas económicas del gobierno militar & 7 \\
\hline $\begin{array}{l}\text { Otras violaciones a los Derechos Humanos (por ej., robo de propiedades de las vícti- } \\
\text { mas) }\end{array}$ & 7 \\
\hline Otras consecuencias económicas negativas de la dictadura (por ej., desindustrialización) & 7 \\
\hline Crisis política previa al golpe & 7 \\
\hline Poder desmesurado de López Rega & 6 \\
\hline Persecuciones & 6 \\
\hline
\end{tabular}

(Continúa) 


\begin{tabular}{|c|c|}
\hline Temas / Ideas principales & Frecuencia \\
\hline Guerra entre dos grupos & 6 \\
\hline Apropiación de bebés & 6 \\
\hline Mundial 78 y su utilización & 5 \\
\hline Juicios y condenas a los militares & 5 \\
\hline Violación a los Derechos Humanos en general & 5 \\
\hline Desinformación / Ocultamiento & 5 \\
\hline Actos terroristas & 5 \\
\hline Surgimiento de Abuelas y Madres de Plaza de Mayo & 5 \\
\hline Conflictos sindicales previos al golpe & 5 \\
\hline Secuestros & 4 \\
\hline Participación de Estados Unidos en el golpe & 4 \\
\hline Clima y humor social tras el golpe & 4 \\
\hline Existencia de centros de detención clandestinos & 4 \\
\hline Destrucción de participación popular & 4 \\
\hline Otras consecuencias negativas de la dictadura & 3 \\
\hline Otras dictaduras en la región & 3 \\
\hline Indultos de Menem & 3 \\
\hline Tensiones internas del peronismo previas al golpe & 3 \\
\hline Desaparecidos por la Triple A & 3 \\
\hline Censura & 3 \\
\hline Exilio & 3 \\
\hline Noche de los lápices & 3 \\
\hline Estado de sitio & 2 \\
\hline Cierre de instituciones & 2 \\
\hline Arresto de Isabel Perón & 2 \\
\hline Leyes de Obediencia Debida y Punto Final & 2 \\
\hline Dolor / Consecuencias psicológicas negativas de la dictadura & 2 \\
\hline Otros & 2 \\
\hline Problemas institucionales del gobierno de Alfonsín & 1 \\
\hline Influencia del establishment en el golpe & 1 \\
\hline
\end{tabular}




\section{REFERENCIAS BIBLIOGRÁFICAS}

Baumeister, R.F. \& Hastings, S. (1998). Distorsiones de la memoria colectiva: De cómo los grupos se adulan y engañan a sí mismos. En D. Páez, J.F. Valencia, J.W. Pennebaker, B. Rimé \& D. Jodelet (Eds.), Memorias colectivas de procesos culturales y políticos [Collective memories of cultural and political processes], (pp. 317-339). Bilbao: Servicio Editorial de la Universidad del País Vasco / Euskal Herriko Unibertsitatea.

Berliner, D. (2005). The abuses of memory: Reflections on the memory boom in anthropology. Anthropology Quarterly, 78, 197-211. http://dx.doi.org/10.1353/anq.2005.0001

Billig, M. (1990). Collective memory, ideology and the British royal family. En D. Middleton $\&$ D. Edwards (Eds.), Collective remembering (pp. 60-80). London: Sage.

Bobbio, N. (1996). Left and right: The significance of a political distinction. Chicago: The University of Chicago Press.

Conway, M.A. (1998). El inventario de la experiencia: Memoria e identidad. En D. Páez, J.F. Valencia, J.W. Pennebaker, B. Rimé \& D. Jodelet (Eds.), Memorias colectivas de procesos culturales y politicos [Collective memories of cultural and political processes] (pp. 49-82). Bilbao: Servicio Editorial de la Universidad del País Vasco / Euskal Herriko Unibertsitatea.

Conway, M.A. \& Pleydell-Pearce, C.W. (2000). The construction of autobiographical memories in the self-memory system. Psychological Review, 107(2), 261-288. http://dx.doi. org/10-10 37/0033-295X.107.2.261

Ferguson, M.J., Carter, T.J. \& Hassin, R.R. (2009). On the automaticity of nationalist ideology: The case of the USA. En J.T. Jost, A. Kay \& H. Thorisdottir (Eds.), Social and psychological bases of ideology and system justification (pp. 53-82). New York: Oxford
University Press. http://dx.doi.org/10.1093/a cprof:oso/9780195320916.003.003

González, M.P. (2012). Historia y memoria del pasado reciente en la escuela: Una mirada a la propuesta oficial [History and memory of the recent past in the school: A look to the official proposal]. Quinto Sol, 16(2), 1-24. Recuperado el 20 de enero de 2015 de http://www. scielo. org.ar/scielo.php?pid=S1851-2879201200020 $0004 \&$ script $=$ sci_arttext

Halbwachs, M. (1980). The collective memory (F.J. Ditter \& V.Y. Ditter, Trads.). New York: Harpers \& Row. Trabajo original publicado en 1950.

Halbwachs, M. (1992). On collective memory (L.A. Coser, Trad.). Chicago: The University of Chicago Press. Trabajo original publicado en 1925.

Herranz, J.K. \& Basabe, N. (1999). Identidad nacional, ideología política y memoria colectiva [National identity, political ideology and collective memory]. Psicología Política, 18, 31-47.

Hirst, W. \& Manier, D. (2002). The diverse forms of collective memory. En G. Echterhoff \& M. Saar (Eds.), Kontexte und kulturen des erinnerns. Maurice Halbwachs und das paradigma des kollektiven gedächtnisses, erinnerns [Contexts and cultures of remembering. Maurice Halbwachs and the paradigm of collective memory]. (pp. 37-58). Konstanz: UVK Press.

Hirst, W. \& Manier, D. (2008). Towards a psychology of collective memory. Memory, 16, 183-200 http://dx.doi.org/10.1080/09658210 701811912

Iñiguez, L., Valencia, J.F. \& Vázquez, F. (1998). La construcción de la memoria y del olvido: Aproximaciones y alejamientos a la guerra civil española. En D. Páez, J.F. Valencia, J.W. Pennebaker, B. Rimé \& D. Jodelet (Eds.), Memorias colectivas de procesos culturales y politicos [Collective memories of cultural and 
political processes] (pp. 265-285). Bilbao: Servicio Editorial de la Universidad del País Vasco / Euskal Herriko Unibertsitatea.

Jost, J., Federico, C.M., \& Napier, J.L. (2009). Political ideology: Its structure, functions and elective affinities. Annual Review of Psychology, 60, 307-337. http://dx.doi.org/10.1146/ annurev.psych.60.110707.163600

Manzi, J., Ruiz, S., Krause, M., Meneses, A., Haye, A. \& Kronmuller, E. (2004). Memoria colectiva del golpe de Estado de 1973 en Chile [Collective memory of the 1973 coup d'état in Chile]. Revista Interamericana de Psicología / Interamerican Journal of Psychology, 38(2), 153-169.

Monsegur, S., Espinosa, A. \& Beramendi, M. (2014). Identidad nacional y su relación con la dominancia social y la tolerancia a la transgresión en residentes de Buenos Aires (Argentina) [National identity and its relationship with social dominance and tolerance transgression in Buenos Aires' residents (Argentina)]. Interdisciplinaria, 31(1), 5-23. http://dx.doi.org/10. 16888/inerd.2014.31.1.1

Muller, F. \& Bermejo, F. (2012). El contagio social, la efectividad del narrador y la discusión como factor moderador [Social contagion, narrator effectiveness, and discussion as a moderating factor]. Perspectivas en Psicología: Revista de Psicología y Ciencias Afines, 9, 44-51.

Muller, F. \& Bermejo, F. (2013). Las fuentes de la memoria colectiva: Los recuerdos vividos e históricos [Sources of collective memory: Lived and historical memories]. Revista de Psicología (Pontificia Universidad Católica del Perú), 31(2), 247-264.

Muller, F., Bermejo, F. \& Addai, A. (2012). Los recuerdos vividos e históricos en la valoración nacional (el capítulo argentino) [Lived and historical memories in national appraisal (the Argentine chapter)]. Acta Psiquiátrica y Psicológica de América Latina, 58(2), 87-94.
Muller, F., Bermejo, F. \& Hirst, W. (2015). Argentines' collective memories of the military junta of 1976: Differences and similarities across generations and ideology. Publicación anticipada en línea. Memory. http://dx.doi.org/10.10 80/09658211.2015.1061013

Muller, F. \& Camarada, R. (2011). Información complementaria, resistencia y efectos subjetivos en la memoria conversacional [Reinforcement, resistance and subjective effects on conversational memories]. Interdisciplinaria, 28(1), 57-72.

Muller, F. \& Hirst, W. (2010). Resistance to the influence of others: Limits to the formation of a collective memory through conversational remembering. Applied Cognitive Psychology, 24(5), 608-625. http://dx.doi.org/10.1002/ac p. 1572

Muller, F. \& Hirst, W. (2014). Remembering stories together: Social contagion and the moderating influence of disagreements in conversations. Journal of Applied Research in Memory and Cognition, 3, 7-11. http://dx.doi. org/ 10.1016/j.jarmac.2013.12.002

Olick, J.K., Vinitzky-Seroussi, V. \& Levy, D. (Eds.). (2011). The collective memory reader. New York: Oxford University Press.

Páez, D., Valencia, J.F., Pennebaker, J.W., Rimé, B. \& Jodelet. D. (Eds.). (1998). Memorias colectivas de procesos culturales y politicos [Collective memories of cultural and political processes]. Bilbao: Servicio Editorial de la Universidad del País Vasco / Euskal Herriko Unibertsitatea.

Rosenberg, T. (1995). The haunted land: Facing Europe's ghosts after communism. New York: Random House.

Schuman, H., Belli, R.F. \& Bischoping, K. (1998). La base generacional del conocimiento histórico [Generational bases of historical knowledge]. En D. Páez, J.F. Valencia, J.W. Pennebaker, B. Rimé \& D. Jodelet (Eds.), Memorias 
colectivas de procesos culturales y políticos [Collective memories of cultural and political processes] (pp. 83-120). Bilbao: Servicio Editorial de la Universidad del País Vasco / Euskal Herriko Unibertsitatea.

Schuman, H. \& Scott, J. (1989). Generations and collective memories. American Sociological Review, 54, 359-381. http://dx.doi.org/10.230 $7 / 2095611$

Stone, C.B., van der Haegen, A., Luminet, O. \& Hirst, W. (2014). Personally relevant vs. nationally relevant memories: An intergenerational examination of World War II memories across and within Belgian French-speaking families. Journal of Applied Research in Memory and Cognition, 3(4), 280-286. http://dx.doi. org/10.1016/j.jarmac.2014.08.00 2

van Dijk, T. (1998). Ideology. Thousand Oaks, CA: Sage.

van Dijk, T. (2003). Ideología y discurso. Una introducción multidisciplinaria [Ideology and discourse. A multidisciplinary introduction]. Barcelona: Ariel. van Dijk, T. (2005). Ideología y análisis del discurso [Ideology and discourse analysis]. Utopía y Praxis Latinoamericana, 10(29), 9-36.

van Dijk, T. (2008). Semántica del discurso e ideología [Discourse semantics and ideology]. Discurso \& Sociedad, 2(1), 201-261.

Vezzetti, H. (2009). Sobre la violencia revolucionaria. Memorias y olvidos [On revolutionary violence. Memories and oblivions]. Buenos Aires: Siglo XXI.

Wertsch, J. (1998). Mind as action. New York: Oxford University Press. http://dx.doi.org/1 0.1093/acprof:oso/9780195117530.001.0001

Wertsch, J.V. (2002). Voices of collective remembering. New York: Cambridge University Press. http://dx.doi.org/10.1017/CBO9780511613715

Zaromb, F., Butler, A.C., Agarwal, P.K. \& Roediger III, H.L. (2014). Collective memories of three wars in United States history in younger and older adults. Memory \& Cognition, 42, 383-399. http://dx.doi.org/10.3758/s 13421-013-0369-7

Departamento de Investigaciones Universidad de Belgrano (UB) Ciudad Autónoma de Buenos Aires - República Argentina

Fecha de recepción: 20 de enero de 2015 Fecha de aceptación: 20 de octubre de 2015 